\title{
23. Shifting Others: Kastom and Politics at the Vanuatu Cultural Centre
}

\section{Benedicta Rousseau}

Assessing the origins of the Bislama term, kastom, anthropologists have highlighted its essentially oppositional nature (Bolton 1999; Lindstrom 1982; Rousseau 2004). Emerging in the context of colonisation and missionisation, kastom provided a discursive marker of a lifestyle apart from that of skul- the way of the mission (Bolton 1999). Over the next century, it found itself enmeshed in a variety of 'evaluative dualisms' (Lindstrom 1982), as practices, material culture and demeanour became linked with the descriptor, kastom. Vanuatu's experience of modernity could be characterised as a series of 'otherings', with the category of kastom positioned in oppositional relationships that provide a definition of indigeneity (Taylor 2010). In some ways, though, kastom works to resist or obscure this action, carrying with it ideological connotations of stability, primordialism, constancy. This chapter seeks to expose the fluidity of kastom, charting the fluctuating relationship between the spheres of kastom and politics over the past 30 years, and the multiple 'others' created through that interaction. ${ }^{1}$

Those familiar with Melanesian anthropology over the last two decades will recognise the dualism of kastom and politics as one of the most over-discussed areas of recent investigation, as well as an ideological opposition that has been employed within Vanuatu. However, the purpose of this chapter is not to rehash arguments surrounding the 'invention of tradition' or the 'hijacking' of kastom by an educated elite (or those who have 'lost theirs' — see Philibert 1986). Instead, I aim to illustrate the way in which kastom relies on its dialectical partners for its definition, and how such partnerships shift. The ethnographic focus for this analysis is the work of the Vanuatu Cultural Centre (VCC) over the past thirty years. The VCC has been chosen for a number of reasons: it holds a unique place in the country as the longest-established state institution to work explicitly in the area of kastom; it has provided a public forum for representations of kastom, creating a repository that enables the type of historical investigation

\footnotetext{
1 This chapter is based on fieldwork carried out in Vanuatu in 2000-01 and 2005. Funding for fieldwork was provided by the Cambridge Commonwealth Trust, the William Wyse Fund, the Emslie Horniman Fund, the Smuts Memorial Fund, the Richards Fund and the British Academy (SG-40371). I am grateful to the Vanuatu Cultural Council for permission to carry out research. I would also like to thank the staff and fieldworkers of the Vanuatu Cultural Centre for their assistance, support and friendship throughout my time in Vanuatu.
} 
necessary to illustrate changes in the relationship between kastom and politics; in addition, anthropological researchers must work through the VCC, so I have been involved in some of the projects discussed below, and affected by the shifting parameters of kastom.

\section{A short history of the Vanuatu Cultural Centre}

A cultural centre was first opened in Port Vila in 1956 by the Condominium administration. It was run by a Board made up of expatriate and indigenous members with facilities comprising a museum, archives and library. Its main aim was to provide for 'the exhibition of objects which illustrate the history, literature and natural resources of the New Hebrides' (Bolton 2003: 3). However, the displays veered away from many objects that would today be labelled kastom, incorporating into the exhibition policy concerns regarding 'heathen' practices that were prevalent amongst some colonial agents, but also expressed through the distinction between kastom and skul employed by many indigenous converts to Christianity. ${ }^{2}$

The arrival in the 1970s of researchers such as Jean-Michel Charpentier and Darrell Tryon, both linguists, Peter Crowe, an ethnomusicologist, and Kirk Huffman, an anthropologist, signalled a shift in the work of the VCC. The previous focus on museum displays lessened in favour of 'getting Melanesians interested' (Bolton 2003: 36). The presence of this new wave of overseas researchers helped push this work into the present, introducing the training of ni-Vanuatu researchers as a key area of VCC work. The reference point for the study of kastom became as much the contemporary practices taking place in island villages as the museum collection in Port Vila.

The Oral Traditions Project was the first project within the VCC to embody this new ethos, and is seen as the start of the fieldworkers' network. Under the tutelage of Peter Crowe, a group of male ni-Vanuatu were trained in the collection of kastom stories and knowledge, with an increasing emphasis on language preservation (through the influence of Darrell Tryon, still the facilitator of the annual men fieldworker's workshop). The effect of this programme of work was manifold: museum and research technologies were dispersed to a wider population than the (expatriate) staff of the VCC (eg: tape-recording, dictionary compilation, orthography etc.); museum work moved away from a simple focus on artefacts; the physical location of research shifted away from Port Vila; and kastom became connected to locality in a new way - the emblematic embodiment of the fieldworker.

2 For a more detailed account of the history and development of the VCC see Bolton 2003. 
This change in orientation coincided with the growth of the independence movement through the 1970s, with the VCC's pro-independence agenda forging a link between political and cultural self-determination; kastom and politics. A key example of this was the National Arts Festival held in 1979 at which groups from around the archipelago were given the opportunity to present 'their kastom' to an indigenous audience. As a key organiser, the VCC took this opportunity to reinforce its message of 'unity in diversity': while kastom took many forms, its existence throughout the proto-state meant it could provide a means of showing how unified ni-Vanuatu were still different from each other, and how 'ownership' of kastom operated at a highly localised level.

\section{Kastom, politics and anthropologists}

It is around this time that anthropologists started to take an interest in the contemporary use of the term kastom, focussing particularly on the way it was being employed by the Vanua'aku Pati. While it had previously served as a means of differentiation from the alternative lifeway of $s k u l$, pro-independence politicians were now using kastom to valorise that which was indigenous, rather than non-Christian. Anthropological critiques of the use of kastom in the rhetoric and practice of the independence movement are numerous, positing an instrumentalist revision of the concept on the part of politicians. These assessments all share a suspicion of - and, in a few cases, an open dislike for-this 'new' type of kastom, and place it in opposition to what they see as having gone before. What unites these otherwise disparate accounts, too, is the construction of a dichotomous relationship between 'national' and 'local' in Vanuatu, frequently tying this to a supposedly temporal dimension of kastom, ideas of authenticity, and insinuations of 'incorrect' practice.

Tonkinson (1982), for example, discusses what he terms 'the problem of kastom in Vanuatu', pointing particularly to a divergence in interpretation amongst different sectors of the population: as ideology on the part of politicians; as pragmatic practice on the part of 'the populace' (Tonkinson 1982: 306). He recounts the uncertainty involved in the interpretation of the new 'valued' kastom on the part of the people of Southeast Ambrym as presented to them by representatives of the Vanua'aku Pati (in this case, a local Presbyterian pastor):

People in some rural areas took the message quite literally. They worried about a return to grass skirts and penis-wrappers, spears and bows and arrows, and wondered whether they would have to destroy non-kastom things such as hunting rifles, aluminium dinghies, outboards and so on (Tonkinson 1982: 310). 
For Tonkinson, the formulation of kastom in the lead-up to independence was so generalised as to become ideology. In fact, he argues that this was inevitable and necessary due to the 'loss of kastom' since European contact:

Kastom has at no stage [in independence politics] been subject to clarification, codification, subdivision or any kind of close analysis or scrutiny. It is, however, hardly surprising that kastom has remained undifferentiated in political discourse, because its utility as a rallying point depends heavily on its confinement to an ideological level, indivisible and unexamined. The reasons for this are obvious, given the circumstances of cultural transformation in Vanuatu, where in many islands a great deal of kastom disappeared virtually without trace and where new patterns of mobility led to widespread diffusion of much of what remained (Tonkinson 1982: 310).

The argument that kastom has/had been 'lost' features again in the work of Philibert (1986). However, for him, it was only certain segments of the population who had lost their kastom - the same group who then attempted to use the concept in the interests of national unity. He argues that 'the protobureaucratic "class" is attempting to gain control over a symbolic code derived from traditional practices (kastom) so as to promote social cohesion and establish a civil polity' (1986: 1). His argument rests on the accentuation of a high level of class differentiation in Vanuatu at the time of independence-in particular, the construction of a homogenous 'elite', composed, it seems, of indigenous politicians. Their use of kastom in the promotion/creation of a national identity is called into question as much for who they are as for how they have defined it:

It is tradition as defined by members of an acculturated political elite living in an urban environment, many of whom were, prior to independence, Presbyterian clergymen or civil servants in the colonial administration. In other words, this kastom policy is endorsed by those least able to define or codify such customs. In fact, one could go further and state that it is a political symbol that could only have been devised in an urban context, away from areas where 'traditional' culture has remained a lived practice (Philibert 1986: 3).

He equates the urban environment, overseas education and state political involvement with a lack of kastom (or 'dead custom, empty practice' (1986: 8))- 'far from being a closely integrated, functionalist view of culture, the view of kastom to emerge from the political circles of the capital is one of a set of survivals. This is so because those who have to decide what kastom was/ is are precisely those who have lost theirs' (1986: 8). The 'incorrect' nature of the concept of kastom propagated in independence politics is addressed again by Larcom $(1982 ; 1990)$. She recounts the lack of interest in the past that she 
encountered during her first fieldwork in the Mewun area of South West Bay, Malakula in the early 1970s. Bernard Deacon, a Cambridge anthropology student, had visited the area some 50 years earlier, and Larcom was keen to build on the ethnographic material provided in his posthumously published papers (Deacon 1934). When she enquired about slit-gong beats and rhythmns - a focus of Deacon's interest - 'no-one...was able or willing to demonstrate them for me' (Larcom 1982: 331). Enquiries relating to other areas of supposed ethnographic interest were no more successful: 'Questions about their parentage or traditions were greeted with about as much interest as a question on the breakfast diet: they could, of course, have told me what they had just eaten for breakfast, but why would I possibly want to know about such things?' (Larcom 1982: 331-2).

On her return in 1981, Larcom found the situation on Malakula much altered, in line with changes in the national arena. Now the Mewun were 'acutely aware of kastom as a body of past traditions to be revitalised' (Larcom 1982: 332). She states that 'kastom was now a critical national and local issue, something representing past authenticity in counterpoint to Western values' (Larcom 1982: 332). For Larcom, the expressions of kastom that she now found did not tally with previous Mewun usage: 'Specific information on the role of kastom in the Mewun past tends to support a view of historic social life as inventive. Kastom glossed today as revealed and revitalised authentic tradition has little to do with earlier use of kastom in Mewun' (Larcom 1982: 333). She emphasises the role of trade, exchange and purchase of kastom in the past - an 'inventive flow' that was also 'mirrored in the looseness of group boundaries' (Larcom 1982: 333). In Larcom's assessment the major change wrought by the model of kastom presented in independence politics was the imposition or adoption of fixity on the 'local' level. She presents this elsewhere as the establishment of a 'museological' version of culture:

By endorsing a museum culture of its own, the nation implicitly challenges a most distinctive aspect of Vanuatu social life - its emphasis on relationships, creativity, and exchange. For many local groups, including the Mewun, the unabashed invention of artifacts as emblems and invitations for relationships may come as close as possible to an authentic ni-Vanuatu culture (Larcom 1990: 188).

In their assessments of kastom these anthropologists foreground an alignment of practice with 'the local' and ideology with 'the national', while an antagonistc division between kastom and politics provides the back-story. These accounts bear the imprint of theoretical preoccupations prevalent in anthropology in the early 1980s, particularly debates surrounding the place of history and tradition in post-colonial politics, exemplified most popularly in the invention of tradition' literature (e.g. Handler and Linnekin 1984; Hanson 1989; Hobsbawm and Ranger 1983). For this reason the examples cited above lean heavily towards 
assessments of authenticity, aiming to demonstrate the lived confusion of rapid political - and discursive - change. I would argue that, while the divisions pointed to by these authors typify the orientation of VCC activity through the 1980s and early 90s, the analysis given fails to pinpoint the reasons why kastom and politics were and had to be kept separate in its work.

On the one hand, the existence and expansion of the fieldworker networkideally including one representative of each language area of the countryreinforced the local nature of kastom. At the same time, the VCC worked to extract its version of kastom from that which could be used for political purposes. The crucial component of this exercise though was not the maintanence of 'purity' or 'authenticity'; rather, it involved the redefinition of the relationship between kastom and land in the post-independence environment. Land alienation had provided one of the strongest propellants of pro-independence politics - for Nagriamel as much as the Vanua'aku Pati-resulting in the return of all land to customary ownership under the constitution of the Republic. ${ }^{3}$ The effect of this was twofold, tying kastom to land but simultaneously introducing the possibility that kastom knowledge could be used to 'prove' customary ownership. ${ }^{4}$ In encouraging the collection, preservation and resuscitation of kastom knowledge and practice, the VCC needed to establish itself as apart from this new, potentially divisive, discourse of kastom.

Assessing this change in the use of kastom in Vanuatu, Bolton states that the Cultural Centre has been consistently opposed to the involvement of fieldworkers in land disputes. While some men fieldworkers are community leaders who may be involved in the arbitration of such disputes, this should remain separate from their role as a fieldworker (2003: 75). Similarly, the use of kastom knowledge that has been collected in the name of the VCC in land disputes is seen to be against the mandate of the organisation (Bolton 2003: 74). In fact, Bolton delineates types of kastom into that which could be used for land disputes, and that which subscribes to the VCC ideal. She describes the Cultural Centre approach in this way:

Land, subject to ownership...can be a source of dispute. While local knowledge and practice, invoked and disputed in conflicts over land, can be described as kastom, the kastom with which the Cultural Centre

3 Section 73 of the Constitution states: All land in the Republic of Vanuatu belongs to the indigenous custom owners and their descendants'.

4 Land disputes are ubiquitous throughout Vanuatu and have been the source of much legal consternation. At one point, 99 per cent of state court judgments relating to land were under appeal. In 2001, the Land Tribunal Act brought into existence a new legal forum for dealing with these disputes, aiming to use kastom processes of justice as well as kastom knowledge as evidence. So far though the Tribunals do not seem to be reducing the number of land disputes passing through the system, and in many areas they are not yet functioning. In addition, many minor court cases that come before island or magistrates courts involving trespass or criminal damage have their roots in land boundary disputes. 
deals is explicitly characterised as uncontroversial. In the Cultural Centre context one fieldworker cannot dispute the knowledge and practice reported by another because each reports on his own place. Kastom is characterised by regional differences: different kastom derives from different places (Bolton 2003: 76).

\section{The Young People's Project: changing conceptions of kastom and research}

While the equation of localised place and kastom provided the orientation of VCC work, and became axiomatic in anthropological writing (eg: Jolly 1994; Bonnemaison 1994), through the 1980s and early 1990s, the VCC itself posed a challenge to this notion with the inception of its Young People's Project (YPP) in the mid-1990s. This project responded to two demographic characteristics of the country that had been so far ignored in most anthropological research and not constituted a place on the agenda of the VCC: urbanisation and the fact that close to 50 per cent of the population was under the age of 25 (National Statistics Office 2000). The Project set out to produce research about young people in Vila, conducted mainly by young ni-Vanuatu themselves using primarily quantitative research methods. Its first two products were a report, Harem Voes blong Yangfala long Vila Taon(VYPP 1999 translated into English as Young People Speak), and a film, Kilim Taem, to accompany the report.

The Director of the Cultural Centre, Ralph Regenvanu, explained the rationale behind the Project's initial research in his introduction to the report. In it he argued that the type of talk that goes on in Vanuatu about young people and their problems is ill-informed and unhelpful, as it is not based on any understanding of the opinions of young people themselves, or an accurate assessment of their situation. The research carried out by the Project could ensure more appropriate development planning, simply by asking young people about their lives:

We can't discuss development if we don't know the fundamental needs and opinions of those at the grassroots level... If we don't know the answers to those questions, then none of us - the government and the people - can find the most appropriate way to address issues facing young people in town today (VYPP 1999: 1, my translation).

This type of research, with its explicit involvement in the development agenda for Vanuatu, indicated a move away from the previous Cultural Centre definition of culture and kastom. This, too, was explained in the introduction: 
Starting in the 1960s, the Cultural Centre has been recording our traditional culture to ensure that there is a record of it for future generations. Now, in the 1990s, we can see that there is a new culture emerging in Vanuatu - this culture is the young people's culture, many of who aren't living kastom but nor are they living a European life. This is a new culture for Vanuatu and it's the work of the Cultural Centre to study this new culture as well, to see how it joins up with kastom and how it is changing our kastom. It is also important to record this major change occurring at this point in the country's history so that we always have a record of it (VYPP 1999: 1-2, my translation).

The effect of the YPP on the work of the VCC was twofold, representing an expansion of the concept of kastom and the introduction of a new range of research methods. This approach was effective in terms of raising the VCC's international profile, in particular gaining praise and support from NGOs and donor agencies and inspiring such organisations to develop projects targeting young people. However, this new synthesis of kastom and formal research methodologies played out less comfortably in the context of the fieldworkers' programme. As mentioned above, one of the key components of YPP activities was to provide training in research methods and data analysis. Those who carried out the research were all young ni-Vanuatu who were not currently employed and had no previous experience of such work. Of those involved in that initial phase of research, some remained part of the project in the new category of YPP fieldworkers. As such, they participated in the annual men and women fieldworker workshops at the Cultural Centre. However, their manner of research and presentation, and, in particular, the way this was received by the older fieldworkers reveals much about the persistence of the connection between locality and kastom favoured by the anthropologists cited above and, up to that point, privileged by the VCC.

The annual workshops provide a focus for fieldworker activities through the year. Separated into two two-week blocks, one each for the men and women, the fieldworkers meet at the VCC in Port Vila to present reports on their work through the year and make presentations on a pre-announced topic. In 2000, the topic for the women fieldworkers' workshop was Kastom kalenda blong garen (the customary gardening calendar), with most presentations covering what gardening activities took place throughout the course of the year; types of crops that were specific to their area and how they had got there; kastom prohibitions relating to gardening practice; and songs and stories relating to all of these. That year, three YPP fieldworkers participated in the workshop, making their presentation as a group.

In locating their sources of information the young women made reference to 'komiuniti blong $m i^{\prime}$ [my community] while also providing information about/ 
from other islands. The fieldworkers were from Tanna, Paama and Matasso, yet they reported details of kastom gardening practice from Ambrym, central and north Pentecost, and south east Malakula, having gained this material through research carried out in a number of areas of Port Vila. Their presentation was mainly met with 'corrections' from the other fieldworkers: the fieldworker from north Pentecost emphasised that you must work every day in the garden, not infrequently - 'if you miss one day, you're hungry for one month'; an Ambrym fieldworker corrected their version of male/female co-operation in gardeningboys are just folem rod, rather than going to the gardens to help. ${ }^{5}$

In response to the latter the YPP fieldworkers stated that this was what they were told, but they were sorry for getting it wrong - an apology that was repeated again later in the session. Other corrections were put forward by the older fieldworkers and, in response to those, the facilitator suggested that practice might be different in town because people haven't been back to the islands for some time, yet this could also be of interest. This was met with general agreement. However, the overall attitude that the young peoples' presentation was in need of correction resulted in one of the YPP fieldworkers breaking down in tears, apologising for her lack of kastom knowledge, stating her desire to go back to her island to learn proper kastom, but explaining that this was hampered by her boyfriend's demands on her and a lack of money. This was met with sympathy from the older fieldworkers.

The tensions that emerged in the workshop's responses to the young people's presentations seem due to the fact that they were either reporting on places that they 'belonged' to but were not living in, or employing 'research methods' to collect information on places that they could not claim to belong to. They were not trying to speak about kastom in town; rather, they attempted to fit into the dominant paradigm of the fieldworker programme that locates kastom in the islands and obscures research methods. As Bolton (2003) argues, legitimation for knowledge in the context of the fieldworker workshops relies on connection to place - with this you are unassailable. Yet how that knowledge is obtained is not always made clear. The position of fieldworker brings with it certain opportunities and 'privileges' — a yearly visit to Port Vila, paid for by the Cultural Centre; access to - and some control over-visiting researchers; and a title that connects the fieldworker to a national institution. Most fieldworkers show a strong commitment to the mandate of the Cultural Centre-blong leftemap kastom - however, the urge for financial gain or the use of their title in local politics is not unknown. While the Cultural Centre sees fieldworkers as representatives of areas beyond just their own village (or family) there is no imperative placed upon them to indicate how representative the knowledge is

5 Literally, 'following the road'. In this instance it implies that the boys are just going to the garden for something to do, rather than work. 
that they present at the workshops. Conflict may come from disputes between families or villages in an area, or sometimes between adherents of different religious denominations (sometimes with differing valuations of kastom).

For the most part, fieldworkers do not make explicit their sources of information. All fieldworkers tend to be of reasonably established status within their village: for men, jifs or of high rank, or connected to a family known to be knowledgeable in kastom; for women, married to such men, or respected as strong women in the village or church hierarchy. For this reason, they can speak without recourse to legitimating sources; their word is enough - they present themselves as natural informants. This is not the case for YPP fieldworkers: they are open to correction due to both their age, and their lack of personal authority. Their use of interviews to gain knowledge from women of islands other than their own, makes clear their inability to speak authoritatively. But, within the workshop model, no legitimating claim can arise from 'research'. The suspect nature of research has been noted by the Director of the Cultural Centre: a researcher is still perceived as someone who comes to Vanuatu, finds things out but neither brings back the knowledge, nor comes back themselves. ${ }^{6}$ Also, when urging women fieldworkers to find out more information from olfala (elders) in their area, the facilitator of the fieldworkers' workshop suggested that they emphasise that 'this is not just research'; rather the women want the knowledge so as to be able to live it in their own lives.

Through the YPP, the VCC undertook an exercise in overt political engagement. However, it was not a direct engagement with state politics, choosing instead to bypass that problematic realm through alignment with external development agencies. While its aim of influencing that sector was successful, the YPP did not break down the definitional boundaries between kastom and politics within the VCC's work - the expansion of the concept of kastom was not accepted in the context of the fieldworkers' workshop; it was seen to contradict the equation of kastom and locality that allowed for the existence of a non-divisive, non-political form of kastom. And, it can be argued that the work of the YPP brought further controversy to the issue through its methodologies, aligning the carrying out of research with a lack of kastom. A more recent VCC initiative may, however, have found a way to move beyond these particular dualisms.

6 Paraphrased from Ralph Regenvanu's presentation to the 'Walking about: travel, trade, migration and movement' conference. ANU; Canberra, October 2000. Anthropologists are generally referred to in Bislama as riseja. 


\section{From politics to policy: the self-reliance and sustainability project}

In March 2005, the VCC organised a meeting held on Uripiv, a small island off the coast of Malakula, to discuss ways of using the 'kastom economy' to achieve what was termed 'national self-reliance'. This was followed up in July 2005 by a larger National Summit on Self-Reliance and Sustainability, held at the Chiefs' Nakamal in Port Vila. The impetus for these meetings came from the 'Traditional Money Banks in Vanuatu' project based at the VCC, but involving collaboration from the Malvatumauri National Council of Chiefs and the Vanuatu Credit Union. Sometimes referred to as the 'pig bank' project, it aims to document and encourage the use of indigenous forms of wealth such as tusked pigs, mats and shell money which play a central role in exchanges and various forms of payment through most parts of the archipelago. ${ }^{7}$ Extrapolating from this project, the activities subsumed under the title of Self-Reliance and Sustainability constituted an entire new mandate for life in Vanuatu. The Uripiv recommendations, and those that came out of the National Summit, covered a variety of topics from reforming the school curriculum to placing a ban on the importation of rice to fundamentally changing the laws governing land tenure.

In a way, the banner of Self-Reliance and Sustainability subsumes multiple projects, with multiple target audiences. As with the YPP, the VCC is courting the NGO/aid donor sector. This is done with a glossy report, featuring a pigtusk-as-art style photo on the cover, written in English predominantly by Kirk Huffman, and containing background information on the traditional economy of areas of Vanuatu such as southern Malakula and North Pentecost where these economic practices are seen as particularly strong. At the same time though, the Uripiv recommendations and, more recently, those of the National Summit have been distributed nationally - to provincial governments, community groups and councils of chiefs - written in Bislama and photocopied on plain A4 paper. ${ }^{8}$

Speaking about the project, the former Director of the Cultural Centre, Ralph Regenvanu, has referred to it as a 'Trojan horse' - a way of making what could be defined as kastom more palatable to the needs or desires of NGOs and government officials. It provides a broken-down version of what the VCC, Malvatumauri and other interested parties believe is kastom, but it is presented in such a way that kastom can appear as a bundle of practices or a resource available to the majority of the ni-Vanuatu population. The Self-Reliance and Sustainability project has required realignments in the relationships between various institutions within

7 This project is funded by UNESCO and the Japanese Funds-In-Trust for the Preservation and Promotion of the Intangible Cultural Heritage.

8 These ideas are updated and explored in more depth in Rousseau and Taylor (in press). 
Vanuatu: government departments, politicians, bureaucrats, the VCC, the Malvatumauri. The Self-Reliance and Sustainability project has also required a broadening of the distribution and efficacy of kastom - it is portrayed as being evenly dispersed throughout society. And, simultaneously, it is demonstrated that kastom holds answers to all spheres of government activity: environment, economy, education, health, justice and governance. Kastom has become, again, a property of the nation, and, as such, the business of the government.

This is not to say that the Self-Reliance and Sustainability project is meeting with universal acceptance. Each bureaucrat that 'sees the light' - that is, reassesses their view of the possible futures of the country with reference to internal (indigenous) rather than external resources - is seen as a victory by many involved. And this points to the new lines of cleavage that I argue are emerging in Vanuatu: kastom was previously assessed on a national/local; ideology/practice continuum, and its legitimacy became anchored in place. Now, it is becoming tied to class issues: the markers of kastom put forward through the Self-Reliance and Sustainability project are economically based, rather than politically based. The ni-Vanuatu middle class may have taken the place of Christians, politicians, young people, researchers, and the urban population as the new 'others' in relation to kastom.

\section{References}

Bolton, Lissant, 1999. Radio and the redefinition of kastom in Vanuatu. The Contemporary Pacific 11(2): 335-60.

Bolton, Lissant, 2003. Unfolding the Moon: Enacting Women's Kastom in Vanuatu. Honolulu: University of Hawai'i Press.

Bonnemaison, Joël, 1994. The Tree and the Canoe: History and Ethnogeography of Tanna. Honolulu, University of Hawai'i Press.

Deacon, A. Bernard, 1934. Malekula: A Vanishing People in the New Hebrides. London: George Routledge and Sons.

Handler, Richard and Jocelyn Linnekin, 1984. Tradition, genuine or spurious. Journal of American Folklore 97: 273-90.

Hanson, Allan, 1989. The making of the Maori: culture invention and its logic. American Anthropologist 91: 890-902.

Hobsbawm, Eric and Terrence Ranger, 1983. The Invention of Tradition. Cambridge: Cambridge University Press. 
Jolly, Margaret, 1994. Women of the Place: Kastom, Colonialism and Gender in Vanuatu. Reading and Chur: Harwood Academic Press.

Larcom, Joan, 1982. The invention of convention. Mankind 13(4): 330-7.

Larcom, Joan, 1990. Custom by decree: legitimation crisis in Vanuatu. In Cultural Identity and Ethnicity in the Pacific, ed. Jocelyn Linnekin and Lin Poyer, 175-190. Honolulu, University of Hawaii Press.

Lindstrom, Lamont, 1982. Leftamap kastom: the political history of tradition on Tanna, Vanuatu. Mankind 13(4): 316-29.

National Statistics Office, 2000. The 1999 Vanuatu National Population and Housing Census: Main Report. Port Vila, National Statistics Office.

Philibert, Jean-Marc, 1986. The politics of tradition: toward a generic culture in Vanuatu. Mankind 16(1): 1-12.

Rousseau, Benedicta and John Taylor (in press). Kastom ekonomi and the subject of self-reliance: differentiating development in Vanuatu. In, Differentiating Development: Beyond an Anthropology of Critique. Soumhya Venkatesan and Thomas Yarrow (eds). Berghahn Books: Oxford.

Rousseau, Benedicta, 2004. The achievement of simultaneity: kastom in contemporary Vanuatu. PhD thesis: Department of Social Anthropology, University of Cambridge.

Taylor, John, 2010. Janus and the siren's call: kava and the articulation of gender and modernity in Vanuatu. Journal of the Royal Anthropological Institute 16(2): 279-6.

Tonkinson, Robert, 1982. National identity and the problem of kastom in Vanuatu. Reinventing Traditional Culture: The Politics of Kastom in Island Melanesia, ed. R.M. Keesing and R. Tonkinson. Mankind, Special Issue 13(4): 306-15.

Vanuatu Yang Pipol's Projek. 1999. Harem Voes Blong Yangfala Long Vila Taon. Port Vila: Vanuatu Kaljoral Senta. 